\title{
NUEVOS CRITERIOS ESTÉTICO-FUNCIONALES DE LAS PANTALLAS ANTIRRUIDO CONSTRUIDAS DE HORMIGÓN
}

(NEW AESTHETIC AND FUNCTIONAL CRITERIA FOR CONCRETE ANTI-NOISE SCREENS)

\author{
Antonio Bello-Morales, Ingeniero y Urbanista
}

CEDEX. MADRID/ESPAÑA

Fecha de recepcion: $24-11-89$

\section{RESUMEN}

El ruido producido por el tráfico vial puede atenuarse actuando en la fuente (el tráfico), en el receptor (las viviendas) o en los espacios exteriores. Desde el aspecto operativo, la via más eficaz e inmediata de conseguir esta atenuación acústica es situar unas pantallas próximas a las vias que, interrumpiendo la trayectoria de la onda sónica, amortigüe el impacto sobre el receptor hasta niveles aceptables. Una pantalla antirruido, por sus características fisicas, debe cumplir dos funciones: acústica y estética. La primera justifica su propia viabilidad y la segunda exige una adecuada inserción en los espacios urbanos. En este trabajo se exponen unos criterios básicos de actuación que sirvan de orientación para conseguir una eficaz ubicación estéticofuncional de las pantallas antirruido en las márgenes de las carreteras o de los ferrocarriles.

\section{SUMMARY}

The noise produced by road traffic can be abated either at the source (the traffic) or at the receiver (housing) or in external space. From the operational point of view, the most efficient and inmediat way of achieving this acoustic abatement is to situate some barriers near the road that interrumpt the path of the sonic waves, lessening the impact on the receiver until it reaches acceptable levels. An antinoise screen, because of its physical characteristics must fullfil two funtions: acoustic and aesthetic. The first one justifies its own viability and the second requieres an adequate insertion in urban spaces. In this work some basic action criteria that serves to guide in the obtaining an efficient aesthetic-funtional position of the anti-noise screens by the sides of roads or railways are developped.
El ruido constituye hoy en dia una molestia ambiental percibida por más del $80 \%$ de los ciudadanos. La protección de nuestros espacios urbanos es por ello una urgente tarea de políticos, planificadores y estamentos locales. Desde el aspecto operativo la atenuación del ruido percibido por el receptor sólo se logra de forma cuantitativa, bien valorable, interponiendo entre receptor y fuente una barrera que obstaculice el paso de la onda acústica provocando su reflexión o su absorción en el seno del mismo material.

De acuerdo con la teoria de la física clásica esta situación genera el fenómeno de la difracción en el borde superior de la pantalla. Es esta difracción lo que realmente provoca la aparición de niveles acústicos importantes por detrás de la barrera, originándose una zona de sombra acústica. Se puede deducir, por tanto, que el ruido percibido por el receptor, situado detrás de una pantalla infinitamente larga, puede llegar por dos vías diferentes:

a) Transmisión.
En el primer caso la onda acústica atraviesa el obstáculo y, ya debilitado, accede al receptor si la barrera no cumple unas determinadas condiciones, especialmente la ley de masas (Fig. 1).
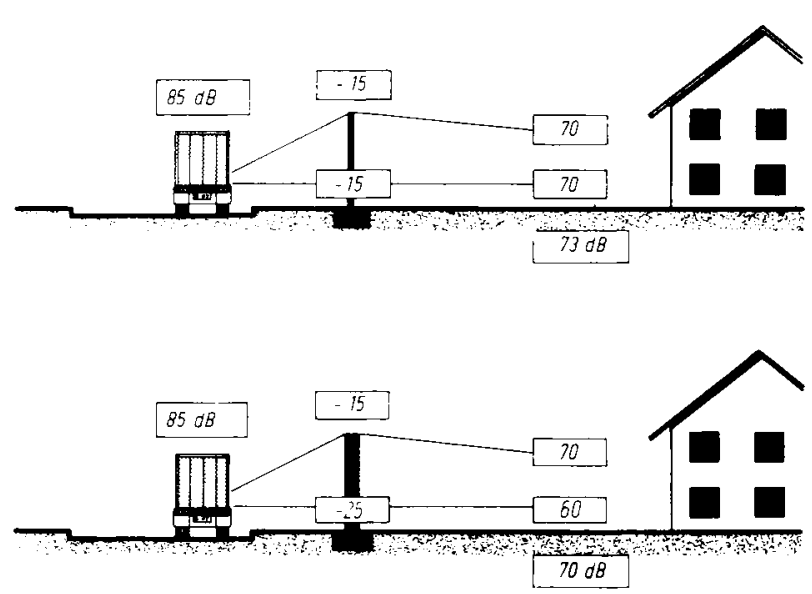

Fig. 1-Eficacia de una pantalla de hormigón respecto a otra pantalla de material ligero. 
En el segundo caso, el sonido llega al receptor una vez que la onda ha superado el borde superior del obstáculo o barrera. La mayor o menor intensidad del sonido que llega en estas condiciones depende fundamentalmente de la altura y de la longitud de la pantalla.

Llegamos, pues, a establecer unos criterios básicos para el diseño y dimensionamiento de las barreras acústicas.

Uno de los aspectos más complejos con que se enfrenta el proyectista de pantallas antirruido es determinar qué material encaja mejor en el sitio, una vez que se haya determinado por cálculo la altura y longitud de la barrera. La experiencia europea establece una amplia gama de posibilidades en cuanto al tipo concreto de material, a su comportamiento acústico y estructural y, desde luego, a su configuración estética. La experiencia indica que las pantallas antirruido deben cumplir tres funciones diferentes:

a) acústica (atenuación de niveles),

b) constructiva (facilidad de montaje y estabilidad),

c) estética (adecuada inserción en el medio).
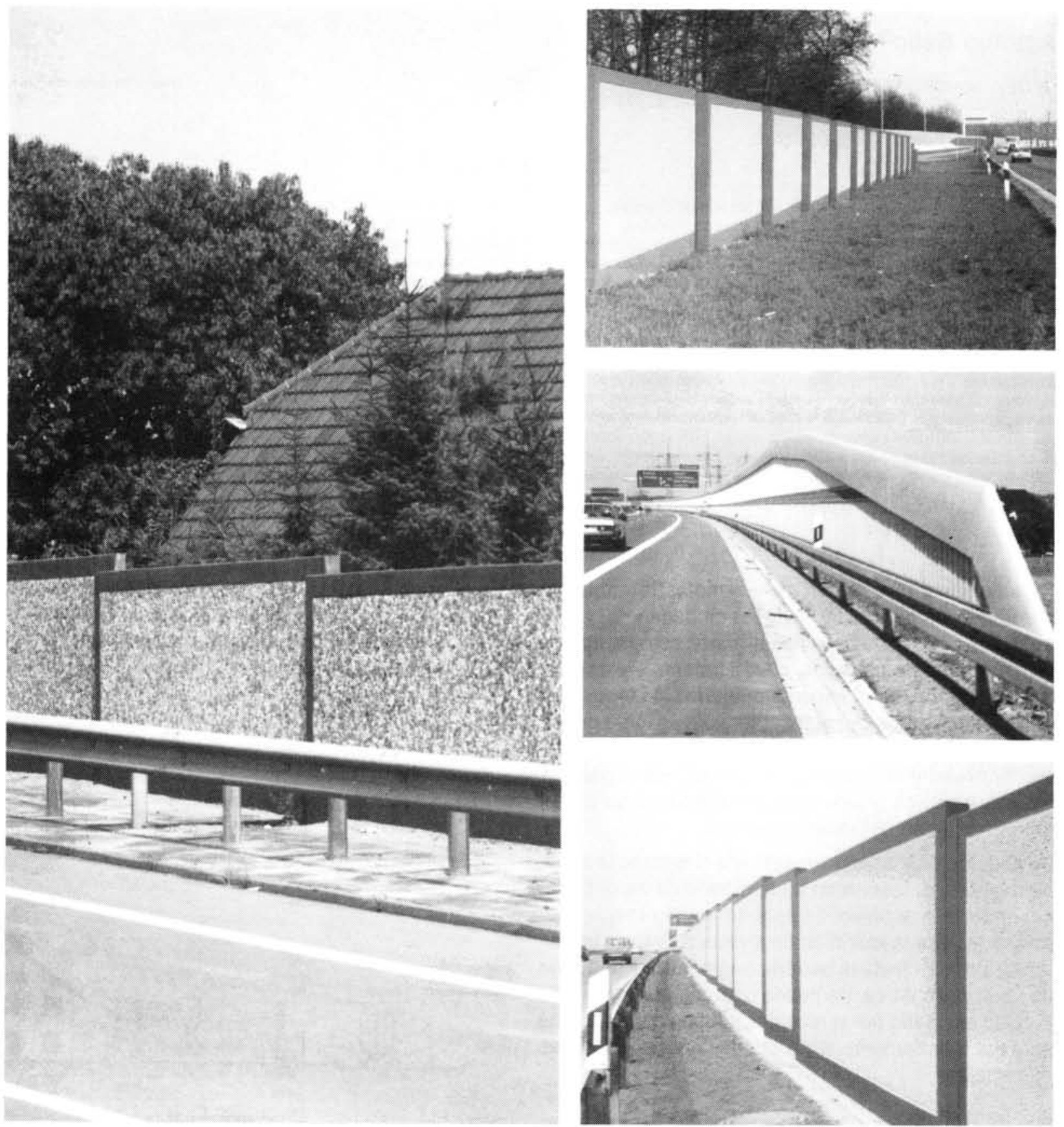

Fig. 2.-Diferentes posibilidades compositivas de pantallas de hormigón. 
Existe una amplia gama de materiales que cumplen rigurosamente las anteriores exigencias pero fundamentalmente las que más se adaptan al medio son las de hormigón y las de aluminio. De hecho en la R.F.A. se construyen casi el $50 \%$ de aluminio y $30 \%$ de hormigón, mientras que en Francia el hormigón se emplea en más del $60 \%$ de los casos.

El hormigón constituye, por tanto, un valioso material muy apto para ser empleado en barreras antirruido cumpliendo adecuadamente las tres funciones a), b), y c) anteriormente expuestas.

\section{Función a}

El hormigón puede satisfacer eficazmente esta condición en su vertiente reflectante o absorbente. En el primer caso se trata de placas o paneles más o menos lisos con nula o escasa absorción acústica. En el segundo caso el hormigón se configura como un conjunto de módulos adecuadamente compuestos para alojar plantaciones en sus oquedades o también como un conjunto de paneles de alineaciones verticales u horizontales compuestos por hormigón poroso de alta capacidad de absorción acústica. Vemos, por tanto, cómo este material puede tener un perfecto encaje en la exigencia acústica-funcional (Fig. 2).

\section{Función b}

Es un hecho conocido que el hormigón es un material pesado y que su transporte en placas o módulos exige el empleo de elementos mecánicos para su manipulación y desplazamiento, especialmente en grandes dimensiones. En el caso de las pantallas antirruido los elementos de hormigón requieren igualmente un adecuado tratamiento. Su transporte no tiene grandes complicaciones con la maquinaria disponible hoy en dia. La colocación en obra igualmente es un proceso relativamente sencillo.

Respecto a la estabilidad estática, al ser un elemento pesado, la componente vertical de su peso propio es elevada y colabora a estabilizar la estructura frente a acciones exteriores como el viento lateral por ejemplo. Sin embargo el mayor peso exige un cuidadoso tratamiento de la cimentación y del lugar de su ubicación sea en zonas próximas al arcén de la carretera o en voladizos de puentes.

\section{Función c}

Las modernas tendencias en el diseño y configuración de las pantallas antirruido abren unas vias de ejecución de estas estructuras considerando la elevada facilidad del hormigón para adoptar infinitas posibilida(c) Consejo Superior de Investigaciones Científicas Licencia Creative Commons 3.0 España (by-nc) des paisajisticas en cuanto a su textura, cromatismo, etc. El tratamiento ambiental de los módulos de hormigón, hábilmente diseñados, aporta una atractiva imagen a un entorno dado en la medida en que pueda combinarse con plantaciones más o menos agrupadas. En el caso de adaptarse el esquema de paneles, se debe. rán diseñar bien su textura y formas aportando elementos vegetales con jardineras de zócalo.

En los últimos años han aparecido nuevas exigencias en los materiales para pantallas antirruido especialmente respecto a:

- la resistencia al fuego,

- corrosión,

- seguridad frente al tráfico,

- conservación,

- aspectos estéticos.

Estas son las razones por las cuales se está recurriendo al uso más intenso de elementos de hormigón. Tal como se ha mencionado con anterioridad las pantallas de hormigón se componen de elementos que constituyen la parte portante $y$, a veces, en el caso de las absorbentes, de una capa de hormigón poroso. El poder absorbente de este hormigón depende de su composición (áridos ligeros y cemento) y del relieve de la capa (nervios, longitudinales o transversales u otras formas geométricas), Fig. 3. Existe en el mercado euro-
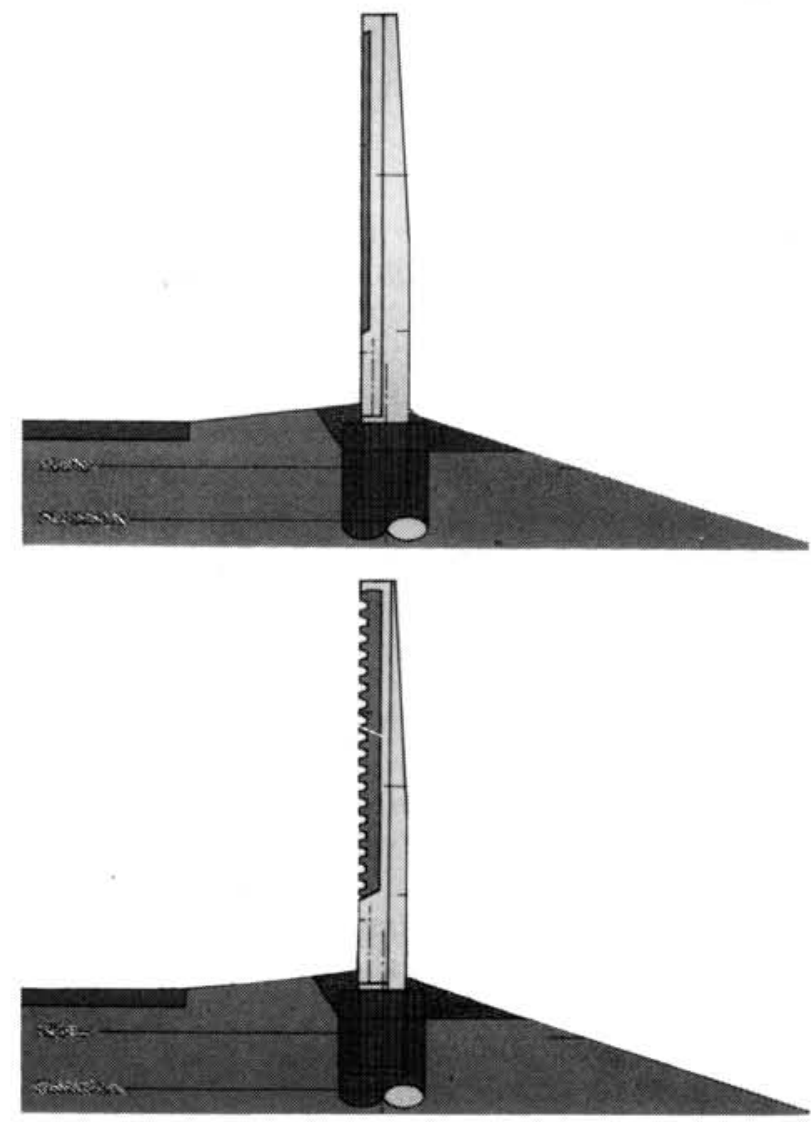

Fig. 3.-Sección de pantallas de hormigón absorbente (arriba) y muy absorbente.

http://informesdelaconstruccion.revistas.csic.es 
peo un gran número de fabricantes de este tipo de paneles acústicos absorbentes. Usualmente tienen una longitud comprendida en 3 y $6 \mathrm{~m}$ y van insertos, por lo general, en soportes entre doble T. El ancho suele ser de 400 a $600 \mathrm{~mm}$. Es muy importante en estos elementos la estanquidad acústica. La cara absorbente puede ser coloreada en toda su masa, mientras que la placa integral de hormigón puede recibir una textura más lisa.

Una de las ventajas de las pantallas de hormigón es que tienen una duración superior a la de los paneles sandwich de aluminio u otros materiales.

Un sistema muy eficaz es el formado por nervios verticales de hormigón poroso que aumenta la superficie de contacto entre la onda sonora y el hormigón ligero, consiguiéndose capacidades de absorción superiores a los $8 \mathrm{~dB}(\mathrm{~A})$.

Por otro lado es posible configurar estas placas absorbentes por ambas caras.

El efecto absorbente de este tipo de paneles depende básicamente de :

- el espesor de la capa absorbente,

- la estructura del hormigón,

- la porosidad,

- la densidad del hormigón,

- factor de superficie.

Respecto al tráfico hay que indicar que aquellas pantallas ubicadas próximas a la calzada pueden colocarse sobre un zócalo firme, el cual podrá configurarse como una barrera de seguridad del tipo rígido (Fig. 4), con lo cual se ahorra la barrera de seguridad flexible usual en nuestras carreteras. De los numerosos ensayos realizados en diferentes paises sobre esta disposición se deduce una eficacia muy buena respecto a la seguridad pasiva, especialmente cuando el ángulo de colisión sea relativamente reducido. En el $90 \%$ de los casos este ángulo es inferior a $10^{\circ}$, en cuyo caso la energia cinética del vehículo se transforma en deformaciones elásticas de los neumáticos y los amortiguadores.

Existe un aspecto muy interesante respecto a los soportes de las pantallas de hormigón que no conviene marginar. Se ha comprobado en el análisis del conjun. to estructural que si las juntas entre placas o entre placas y soportes no sobrepasan del $1 \%$ de la superficie total de la pantalla, la eficacia global sólo se reduce hasta un valor comprendido entre 0,5 y $1 \mathrm{~dB}(\mathrm{~A})$, apenas perceptibles por el receptor afectado. En caso contrario hay que aplicar un tratamiento especial a las juntas mediante tres soluciones (Fig. 5):

(c) Consejo Superior de Investigaciones Científicas

Licencia Creative Commons 3.0 España (by-nc) a) con juntas de neopreno o similar,

b) juntas machihembradas o escalonadas,

c) tapajuntas.

Se trata en definitiva de hacer el conjunto de la pantaIla totalmente estanca a la onda sonora.

En el aspecto estético-paisajístico conviene tener en cuenta que la variación de altura por razones compositivas conviene no sobrepase del $10 \%$ de la altura total dada por consideraciones puramente acústicas, con lo cual se puede, en un margen ópticamente razonable, combinar adecuadamente las diferentes alturas en alzado y en sección aportando ondulaciones o escalonamientos bien distribuidos y compensados de manera

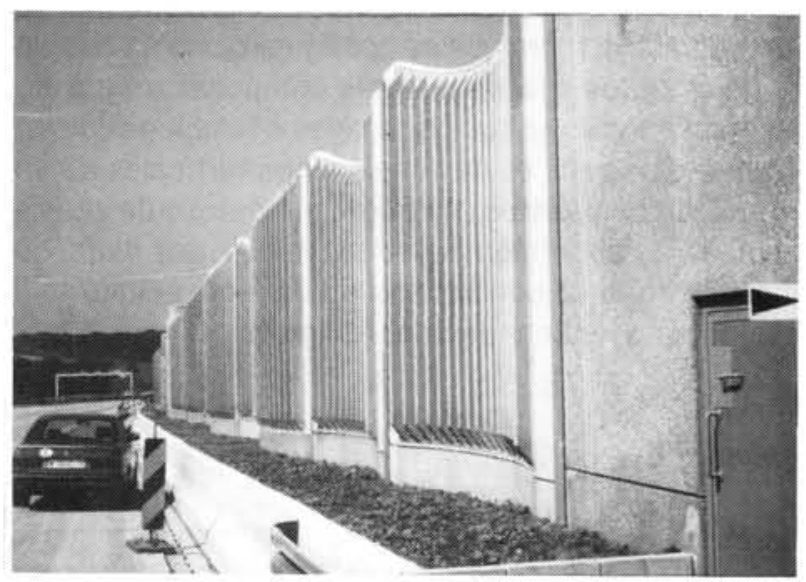

Fig. 4.-Atractiva solución de unas pantallas construidas de hormi. gón armado.
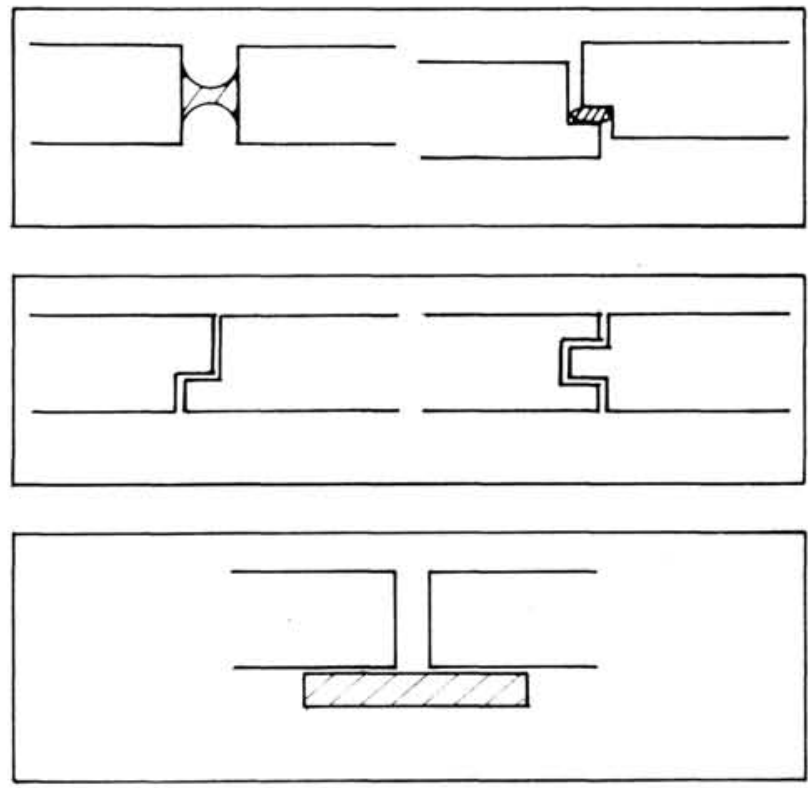

Fig. 5.-Diferentes tratamientos de las juntas de pantallas de hormigón.

http://informesdelaconstruccion.revistas.csic.es 


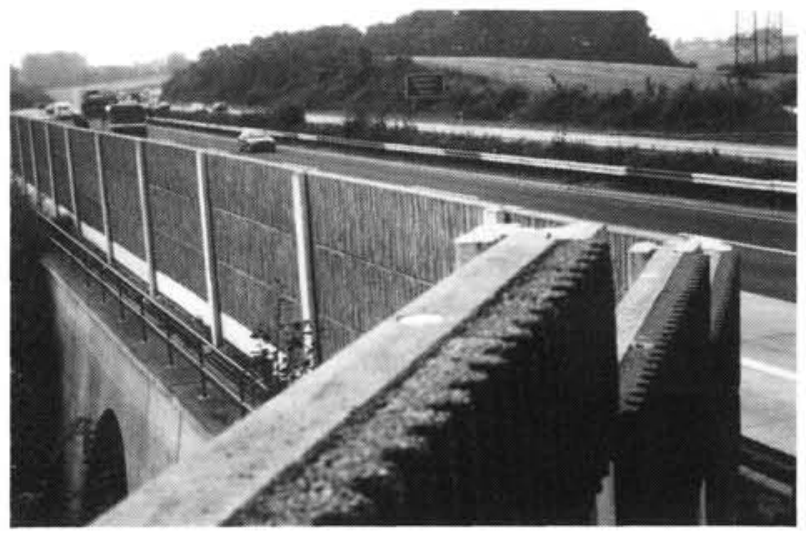

Fig. 6.-Tratamiento muy absorbente de los paramentos de esta pan. talla de hormigón.

que se cree un conjunto armonioso y equilibrado (Fig. 6). Esto tiene mayor importancia en el caso de largos tramos continuos, en donde hay que evitar la monotonia. En este supuesto es preferible opefar por zonas. Es decir dividir el tramo en varios sectores cuya dimensión lineal esté relacionada con algún elemento am. biental, como por ejemplo la vegetación. En este caso se aplica un criterio coherente en cuanto a la textura, cromatismo y forma en alzado y planta. Con este pro-

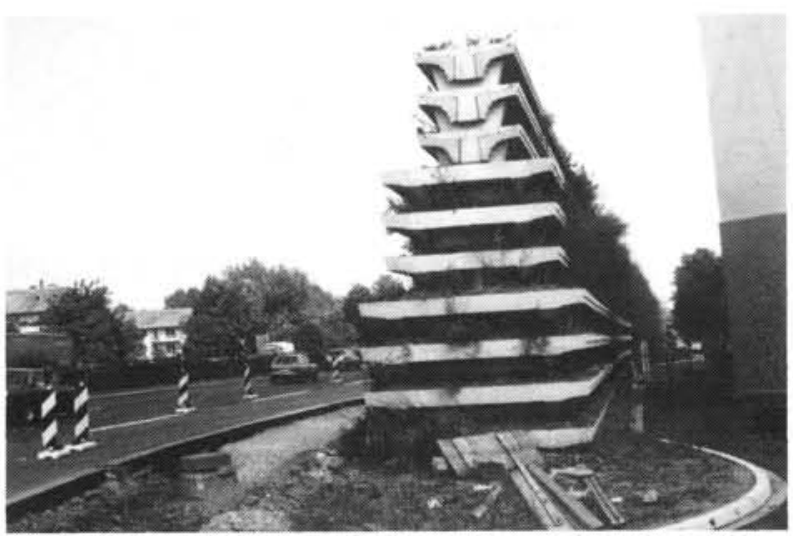

Fig. 7.-Eficaz combinación de módulos de hormigón con plantaciones.

cedimiento se obtiene un tramo largo dividido en sectores siempre adaptados a cada uno de los entornos o elementos periféricos (Fig. 7).

El proceso anterior ha sido empleado con gran acierto y eficacia en largos tramos de pantallas de la periferia de Paris y en la Cuenca Alemana del Ruhr. Se consigue en definitiva un esquema global variable, ameno y de gran eficacia paisajistica.

\section{BIBLIOGRAFÍA}

ADAC. Strassenverkehrslärm. 1979.

BAUM, F. "Praxis des Umweltschutschutzes». Oldenburguerverlag, Munich, 1979.

BAUSCH Dieter. "Lämschutz an Strassen". Bundesverband der Deutschen Zementindustrie, Colonia.

BELLO-MORALES MERINO, Antonio. "Las nuevas Ciudades Residenciales». Editorial Dossat, Madrid, 1978.

BELLO-MORALES MERINO, Antonio "Tratamiento Estético, Paisajistico y Funcional de las Carreteras mediante Plantaciones". AIPCR, Madrid.

BOHNY, Michel et al. "Lärmschutz in der Praxis". Oldenburgverlag, 1986.

BUNDESMINISTER FÜR VERKEHR (R.F.A.). «Richtilinien fün den Lärmschutz an Strassen». RLS-81 1981.

DIN 18005 "Schallschutz in Städtebaun, 1976.

FORSCHUNGSGESELLCHAFT FÜR STRASSEN UND VERKEHRSWESEN. "Empfehlungen für die Gestaltung von Lärm. schutzanlagen an Strassen". Colonia, 1985.

FORSCHUNGSGESELLSCHAFT FÜR STRASSEN UND VER. KEHRSWESEN. "Richtilinien für die Anlagen von Strassen". Colonia, 1980.

KRELL, Karl. "Handbuch für Lärmschutz and Strassen und Schienenwegen». Otto Asner Verlaggesellschaft.
GRUBER, H. "Geschwindigkeitsbeschränkung an Autobahmen. Lärmbekampfung heute». 1978.

MACHTEMES, A. "Schallschutz im Städtebau". 1980.

MENSEBACH, Wolfgang. "Strassenverkehrstechnik». Wernerverlag, 1983.

MINISTERIE VAN OPENBARE WERKEN. "Tijdchrif der Openbare werten van België". 6, 1975.

OSTERREICHEISCHES ARBEITSRING FÜE LÄRMBEKÄMP. FUNG. "Lämbekampfung, Heute und Morgen".

REINHOLD, G. "Schalltechnische Anforderungen an Lärm. schutzwände". Heft 2/75.

SÄLZER, Elmar, "Städtebaulicher Schallschutz". Bauverlag Wiesbaden-Berlin.

SCHIRMER, W. "Lärmbekämpfung". Tribüne Verlag Berlin, 1971.

STICH-TING STUDIE CENTRUM WEGENBOW. "Bomen en Struiken Langs". Wegln, Delf, 1981.

ULRICH, S. "Zur Berechnung der Schutzwirkung von Trogbauwerken». Enero, 1977.

VDI 2714. "Schallausbreitung im Freien". (12/76).

VDI 2573. "Schutz gegen Verkehrslärm". (2/74).

WORLD HEALTH ORGANIZATION. "Assessment of Noise Im. pact on the Urban Environment". Copenhagen, 1986. 